\title{
Counter-Narrative of Terrorism and Religion Violence in Islamic Boarding School
}

\author{
Ahsani Taqwim Aminuddin ${ }^{1}$ \\ Magister Ilmu Komunikasi, University of Diponegoro - Indonesia
}

Abstract

This study aims to describe narrative texts held by Islamic boarding schools to fight terrorism or violence narratives and to describe activities carried out to support existing narrative texts. This study uses the Discourse Analysis method and divides the two stages of analysis. At the text analysis stage, the Islamic boarding school's narratives were analyzed using the Presidential Identity Prisma, while in the context analysis phase, the results of interviews and research observations were analyzed with Communication Performance to determine organizational culture and routine activities in Islamic Boarding Schools. The main theory used in this study is Fisher's Narrative Theory, which describes human decisions in believing in a narrative or story and acting on the belief in the story. According to Fisher, humans believe a narrative is influenced by the rationality of narratives, where the narrative has consistency and truth. The results of this study indicate that narrative texts have dominant Islamic boarding schools having coherence in the aspect of objectives that focus on the production of a message of peace so that Indonesia remains a country with a tolerant society and can manage existing differences. The figure of the Prophet Muhammad in the narrative is described as a person who prioritizes deliberation in solving problems. The Nahdlatul Ulama organization is also an organization that has the task of maintaining the unity of the people and nation of Indonesia in the midst of differences. Whereas, the efforts made to support narration are to routinely teach Islamic values as a religion of love in each forum; Reforming the education system; checking curriculum sourced from the government or from outside; Caregivers of Islamic boarding schools routinely form narratives to prevent terrorism, which are printed into books, sent to the media and so on so that the audience can easily access.

Keywords: Counter-Narrative; Prevention of Terrorism; Fight Religious Violence.

\footnotetext{
1 Ahsani Taqwim Aminuddin is a student at University of Diponegoro, Indonesia. E-Mail: ahsanitaqwem@gmail.com
} 
Kontra-Narasi Terorisme dan Kekerasan Agama di Pondok Pesantren

Ahsani Taqwim Aminuddin

I. Pendahuluan

1.1. Latar Belakang

Kasus terorisme pada era reformasi di Indonesia banyak dikaitkan dengan kejatuhan Presiden Soeharto dengan peningkatan kasus terorisme dan kekerasan yang terjadi di Indonesia. Pada periode tersebut, Indonesia menyaksikan bangkitnya gerakan ekstremisme berdasarkan paham keagamaan (Islam), munculnya politik identitas yang didasari pada keyakinan orang-orang yang percaya bahwa Islam terancam dan penganutnya diwajibkan untuk membela Islam dari ancaman tersebut (Lim, 2005:2). Hingga tahun 2018 tindakan terorisme yang mengatasnamakan agama masih kerap terjadi di Indonesia, dan hal ini diyakini disebarkan dan dikembangkan di beberapa kelompok masyarakat di berbagai daerah. Sepanjang tragedi aksi teror di Indonesia, terorisme atas nama agama adalah yang paling dikenal. Paska meledaknya bom di hotel Ritz-Carlton dan JW Marriot pada 17 Juli 2009 di Jakarta, muncul kecurigaan dan pandangan negatif bahwa pesantren dan sekolah Islam di Indonesia memiliki hubungan dengan ideologi Islam radikal (Nakamura, 1983). Pelaku teror, seperti Imam Samudera, Amrozi, Ali Imron, Ali Ghufron, dikenal sebagai orang-orang pesantren yang berasal dari Lamongan, Jawa Timur. Setelah peristiwa itu, tidak sedikit tuduhan yang menyerang pesantren sebagai tempat berkembangnya terorisme dan pemahaman ekstrimisme, meskipun pada akhirnya image negatif tersebut bertahap diperbaiki.

Beberapa upaya penanggulangan paham terorisme dan kekerasan agama dianggap tidak berjalan sesuai harapan dan dianggap belum efektif sehingga menimbulkan penolakan beberapa pihak. Menurut Ketua Umum PP Muhammadiyah, Haidar Nasir, program deradikalisasi merupakan konsep yang baik, namun setiap bentuk kontra selalu menimbulkan benturan keras di lapangan. Selain itu, BNPT dan Kementerian Komunikasi dan Informasi memblokir beberapa situs online yang dianggap menebarkan paham radikalisme, yang pada akhirnya menuai pro dan kontra karena dianggap mengikis demokrasi. Tindakan ini mengindikasikan bahwa BNPT masih reaktif terhadap tren dan tidak memiliki kebijakan komunikasi strategis yang koheren, 
yang dapat mendorong keterlibatan berkelanjutan yang melibatkan kepercayaan dari khalayak sasaran mereka.

Pemerintah Indonesia, dalam hal ini BNPT dengan menggunakan situs resmi miliknya untuk menciptakan kesadaran dan melibatkan khalayak untuk melawan narasi teroris. Namun, aktivis LSM menganggap dibutuhkan keterlibatan organisasi masyarakat dan keagamaan di Indonesia ikut serta dalam upaya melawan narasi radikal-ekstrim. Di beberapa negara seperti Amerika Serikat, Inggris dan Belanda, upaya perlawanan terhadap terorisme saat ini dilakukan dengan melawan narasi ekstremisme yang dinilai menjadi penyebab utama timbulnya ideologi radikal ekstrim tersebut. Strategi pencegahan terorisme Inggris menyatakan prioritas tertinggi saat ini dalam kontra-terorisme didasari oleh aktivitas yang menentang ideologi teroris, misalnya melawan narasi teroris, dengan melibatkan masyarakat. Sedangkan di Indonesia, organisasi seperti Nahdlatul Ulama (NU) dan Muhammadiyah menciptakan narasi untuk melawan propaganda dan memerangi pesan-pesan terorisme di Indonesia dengan melibatkan sejumlah masyarakat sipil dan organisasi keagamaan yang berbeda, termasuk Pondok Pesantren. Penelitian yang dilakukan oleh Woodward, Rohmaniyah, Amin and Coleman (2010:36-37), membantah keterlibatan pesantren dalam pertumbuhan kelompok teror berdasarkan agama. Pendidikan agama yang diterima remaja di pesantren tidak mendorong mereka menuju ekstremisme, malah justru sebaliknya. Pesantren membantu untuk membentengi mereka terhadap radikalisme/ekstrimisme.

\subsection{Rumusan Masalah}

Berdasarkan pemaparan di atas maka pertanyaan penelitian yang dapat dirumuskan dalam studi ini adalah:

(1) Bagaimana teks narasi yang digunakan di Pondok Pesantren untuk melawan narasi terorisme dan kekerasan agama?

(2) Hal apa saja yang dilakukan pihak Pondok Pesantren untuk mendukung narasi yang dimiliki?

\subsection{Tujuan penelitian}

Berdasarkan rumusan masalah yang ada maka tujuan dilakukannya penelitian ini adalah untuk mengetahui teks narasi yang digunakan Pondok Pesantren dalam upaya melawan narasi terorisme dan kekerasan atas nama agama; serta untuk mengetahui tindakan yang dilakukan oleh Pondok Pesantren untuk mendukung teks narasi yang dimiliki.

\subsection{Kegunaan Penelitian}

Adapun manfaat yang diharapkan dapat diperoleh dari penelitian ini adalah: (1) Kegunaan Akademis, penelitian ini diharapkan dapat memberikan kontribusi bagi penelitian ilmu komunikasi khususnya mengenai pemahaman 
yang lebih mendalam mengenai Teori Naratif dan Komunikasi Pencegahan Terorisme dalam hal ini kontra-narasi; (2) Kegunaan Praktis, penelitian ini diharapkan dapat memberikan kontribusi praktis dalam komunikasi dan upaya melawan terorisme yang melibatkan organisasi atau komunitas di tingkat lokal seperti Pondok Pesantren; (3) Kegunaan Sosial, studi ini diharapkan dapat menjadi referensi terkait strategi mencegah dan melawan narasi terorisme dengan melibatkan komunitas lokal, yakni Pondok Pesantren. Penelitian ini mengkaji narasi yang digunakan untuk melawan narasi terorisme serta tindakan yang dilakukan untuk mendukung narasi yang di produksi dimiliki.

\section{Tinjauan Literatur}

2.1. Penelitian Terdahulu

Beberapa penelitian yang telah dilakukan dalam kajian ilmu komunikasi untuk menganalisis upaya pencegahan terorisme di beberapa negara salah satunya adalah penelitian yang dilakukan oleh Anne Aly, Dana Weimann-Saks, and Gabriel Weimann (2014). Penelitian dengan judul Making 'Noise' Online: An Analysis of the Say No to Terror Online Campaign ini menganalisis teks kampanye anti-teror "Say no to terror". Dengan menggunakan metode penelitian analisis deskriptif kualitatif peneliti melakukan analisis pada 15 video dan tulisan dalam situs web. Hasil dari penelitian ini adalah narasi kontraterorisme menawarkan beberapa wawasan tentang bagaimana unsur-unsur dari teori Noise diterapkan dalam kontra-narasi, seperti: kredibilitas, terminologi, tradisi, afiliasi, dan strategi bertindak lokal-berpikir global.

Di konteks Indonesia sendiri, penelitian dari Irfan Abubakar (2016) dengan judul Effective Strategic Communication in Countering Radicalism in Indonesia menjelaskan bagaimana upaya pencegahan terorisme dengan pendekatan melalui media kontemporer. Penelitian ini menganalisis narasi pencegahan terorisme oleh BNPT dan Lazuardi Birru dalam mengampanyekan anti-terorisme dan kekerasan. Ada 5 narasi yang dianalisis dalam penelitian ini, dan menunjukkan hasil bahwa narasi yang dibentuk dan dikomunikasikan oleh BNPT adalah narasi yang mencoba untuk meningkatkan dan menciptakan rasa cinta tanah air, mengembalikan citra Islam sebagai agama rahmat dengan sasaran yang spesifik yakni generasi muda muslim khususnya yang aktif dalam berkomunikasi menggunakan dunia maya, atau media kontemporer.

Selanjutnya, penelitian yang dilakukan oleh Christine Archetti dengan judul Are the Media Globalizing Political Discourse?: The War On Terrorism Case Study (2014), memiliki fokus utama untuk menantang klaim bahwa media yang semakin global menciptakan homogenisasi wacana politik di tingkat internasional. Penelitian ini menganalisis 11 isi wacana media (artikel surat kabar nasional) dan 12 wacana politik (pernyataan publik pemerintah) dalam berbagai kasus internasional yakni A.S., Italia, Prancis dan Pakistan. Metode analisis menggabungkan teori framing dengan analisis wacana kritis. Teori yang 
digunakan adalah teori Framing. Hasil dari penelitian ini menjelaskan bahwa tidak ada bukti globalisasi wacana politik atau media, apalagi imperialisme budaya dari pihak pemerintah Amerika. Budaya lokal merupakan penentu utama dalam menentukan konten media lokal, bahkan dengan adanya usaha persuasi, aktor lokal secara aktif menafsirkannya kembali narasi dengan cara sesuai dengan kepentingan jangka panjang mereka.

\subsection{Teori Naratif Fisher}

Di dalam kajian Ilmu komunikasi, Naratif diperkenalkan oleh Fisher, dengan menyebutnya sebagai Paradigma Naratif. Asumsi dari teori narrative menurut Fisher yaitu: (1) Manusia pada dasarnya makhluk pencerita; (2) Keputusan mengenai sebuah cerita didasarkan pada pertimbangan yang rasional. Menurut Fisher, saat orang mendengarkan cerita berlawanan maka mereka akan memilih salah satunya; (3) Pertimbangan dipengaruhi oleh sejarah, biografi, budaya dan karakter; (4) Rasionalitas didasarkan pada penilaian orang mengenai konsistensi dan kebenaran sebuah cerita; (5) Kita berada di dunia yang diisi dengan cerita, dan kita harus memilih cerita yang ada (West and Turner, 2008:46).

Rasionalitas Naratif memberikan khalayak sebuah cara untuk menilai naratif yang akan dipilih atau ditolak. Konsep Rasionalitas Naratif beroperasi berdasarkan dua prinsip, yakni: (1) Koherensi, yaitu standar yang penting dalam menilai rasionalitas naratif. Koherensi sendiri didasarkan pada tiga tipe konsistensi yang lebih spesifik, yaitu koherensi struktural (tingkatan dimana elemen-elemen dari sebuah cerita mengalir dengan lancar), koherensi material (tingkat kongruensi antara satu cerita dengan cerita lainnya yang seperti terkait), koherensi karakterologis (merujuk pada dapat dipercayainya karakter-karakter dalam cerita); (2) Kebenaran, yakni prinsip rasionalitas naratif yang menilai kredibilitas dari sebuah cerita. Dalam penelitian ini, konsep kebenaran dikembangkan menjadi kesejajaran naratif, dimana narasi yang diterima oleh khalayak adalah narasi yang didukung dengan tindakan (West and Turner, 2008:51-53).

\subsection{Narasi Kontra Terorisme sebagai Brand}

Di dalam buku Understanding Terrorism in the Age of Global Media, Archetti menganggap naratif sebagai sebuah brand yang nantinya akan ditawarkan ke khalayak sasaran. Narasi dibangun secara sosial dan berkontribusi pada pembentukan identitas khalayak yang telah dibentuk dan dipertahankan sesuai dengan kehendak individu atau kelompok tersebut. Dengan menggunakan konsep Prisma Identitas Kapferer, Archetti memetakan sebuah narasi, baik milik Al-Qaeda maupun milik pemerintah untuk melawan narasi teror. Menurut Kapferer (2004; dalam Archetti, 2013:153-157) terdapat enam aspek prisma, antara lain: 
- Aspek physique (tujuan utama narasi), aspek ini dapat dianggap mencakup tujuan utama yang ditentukan oleh organisasi dalam narasi.

- Aspek Personality (tokoh/karakter yang dimunculkan dalam narasi).

- Aspek Culture (nilai-nilai moral dalam narasi), aspek ini menunjukkan nilai yang mencirikan naratif kelompok;

- Aspek Relationship, adalah tentang hubungan antara warga negara di masyarakat seperti "toleransi dan kesetaraan semua pihak";

- Aspek Reflected Consumer, mencakup hal yang diinginkan/bagaimana tindakan yang diharapkan dari khalayak;

- Aspek Self-image, mencakup hal bagaimana khalayak dipandang (cara masyarakat ditampilkan.

Gambar 1. Prisma Identitas Kapferer

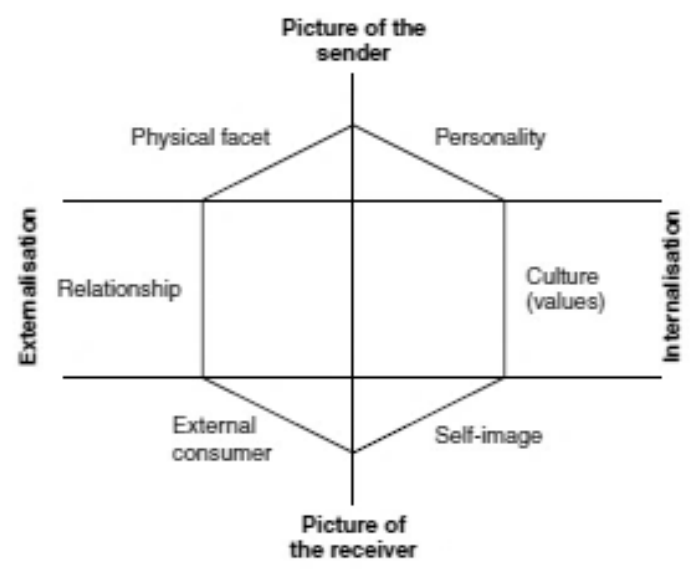

\subsection{Teori Budaya Organisasi}

Organisasi adalah wadah sekelompok orang dengan tujuan yang sama. Budaya organisasi dalam perspektif interpretif dilihat sebagai proses pembentukan pemahaman yang membentuk realitas organisasi. Budaya organisasi menurut Smircich (1983) merupakan proses atau pemahaman dalam sebuah organisasi. Reaksi atas pesan yang diinterpretasikan dan disampaikan oleh sebuah organisasi tidak akan cermat tanpa adanya pengetahuan mengenai konteks organisasi. Sehingga untuk memahami budaya organisasi, perlu diketahui bagaimana organisasi menggunakan bahasa untuk mengetahui budaya organisasi (Pace \& Faules, 92-105:2002).

Komponen penting yang perlu diperhatikan untuk mengetahui Budaya Organisasi dijelaskan oleh Pacanowsky dan O'Donello Trujillo (West \& Turner, 325:2008) sebagai sebuah metafora yang menggambarkan proses simbolik dari pemahaman dan perilaku individu dalam sebuah organisasi yang disebut performa. Performa dijabarkan menjadi lima performa budaya, yakni: 
- Performa ritual, yaitu performa komunikasi yang terjadi secara teratur dan berulang dalam sebuah organisasi. Performa ritual ini terdiri dari empat jenis: ritual personal (hal yang dilakukan pemimpin atau anggota secara rutin dalam organisasi), ritual tugas (perilaku rutin yang dikaitkan dengan pekerjaan, ritual sosial (rutinitas yang mempertimbangkan interaksi dengan individu lain), dan ritual organisasi (kegiatan yang sering dilakukan dalam lingkup organisasi).

- Performa hasrat, yaitu kisah atau cerita yang berkaitan dengan organisasi yang sering diceritakan ulang secara antusias oleh pemimpin atau anggota kepada anggota lain, baik yang baru maupun yang lama.

- Performa sosial, yaitu perpanjangan sikap sopan santun untuk membangun kerja sama antar anggota dalam sebuah organisasi.

- Performa politis, yaitu upaya untuk mempengaruhi, menguasai dan mengontrol orang lain dalam organisasi tersebut.

Performa enkulturasi, yaitu upaya yang dilakukan dalam organisasi untuk membantu anggotanya menemukan pengetahuan dan keahlian sebagai anggota organisasi agar dapat memberikan kontribusi.

III. Metode Penelitian

Tipe penelitian ini adalah deskriptif kualitatif. Penelitian ini akan mendeskripsikan narasi yang dimiliki oleh Pondok Pesantren untuk melawan narasi terorisme dan juga mendeskripsikan tindakan yang dilakukan untuk mendukung narasi yang telah ada. Data dalam penelitian ini adalah teks narasi milik Pondok Pesantren untuk melawan narasi terorisme dan narasi kekerasan atas nama agama. Selain data teks, data berupa hasil wawancara dengan pengurus dan pengasuh pesantren juga dibutuhkan untuk mengetahui kegiatan yang dilakukan oleh pengurus organisasi untuk mendukung narasi yang telah ada. Data teks yang menjadi tema utama yang terus digunakan Pondok Pesantren dalam upaya melawan narasi terorisme, diantaranya narasi dengan tema "Toleran pada Perbedaan Keyakinan; Perbedaan Pilihan Politik; dan Makna Jihad."

\subsection{Teknik Pengumpulan Data}

Dasar pertimbangan sebagai daerah yang memiliki sejarah panjang tentang kasus terorisme di Indonesia, yaitu Malang, Jawa Timur, menjadi lokasi penelitian ini dilakukan. Jawa Timur juga dikenal sebagai daerah dengan perkembangan Pondok Pesantren yang pesat di Indonesia. Penelitian ini difokuskan pada Pondok Pesantren Al-Khoirot Malang, salah satu Pondok Pesantren di daerah Malang, Jawa Timur, yang juga memiliki afiliasi dengan salah satu organisasi Islam terbesar di Indonesia, yakni Nahdlatul Ulama. Data dalam penelitian ini dikumpulkan dengan melakukan kajian teks terhadap narasi milik Pondok Pesantren. Tahap selanjutnya peneliti melakukan pengumpulan data berupa indepth-interview dengan pengasuh dan pengasuh Pondok Pesantren. 


\subsection{Analisis Data}

Teknik analisis data penelitian ini menggunakan analisis wacana. Analisis wacana tidak hanya menganalisis teks narasi yang telah didapatkan dari masing-masing komunitas lokal, namun juga menganalisis konteks narasi yang berupa data hasil wawancara dengan anggota komunitas dan observasi (Cook, 2:2005). Pada tahap pertama, data teks yang didapatkan di lapangan (berupa narasi milik pondok pesantren), dianalisis menggunakan perangkat Prisma Identitas Kepferer, untuk mengetahui struktur dari teks narasi masing-masing komunitas lokal. Terdapat enam aspek prisma identitas Kepferer seperti yang telah dijelaskan sebelumnya.

Pada tahap kedua, level konteks, dilakukan analisis pada data yang didapatkan melalui wawancara mendalam dengan pihak/anggota masingmasing kelompok lokal. Dari sejumlah data yang didapatkan, dilakukan kategorisasi data untuk dapat memfokuskan hanya pada data yang dibutuhkan dalam penelitian. Kategorisasi data dilakukan berdasarkan pada lima Performa Komunikasi seperti yang telah dijelaskan sebelumnya.

Tabel 1. Level Analisis Wacana dalam penelitian

\begin{tabular}{|c|c|c|}
\hline Level & Jenis & Sumber data \\
\hline \multirow[t]{2}{*}{ Teks } & Primer & $\begin{array}{l}\text { Teks narasi milik Pondok Pesantren yang } \\
\text { dianalisis menggunakan Prisma Identitas } \\
\text { Kepferer }\end{array}$ \\
\hline & Sekunder & Hasil penelitian lain yang relevan \\
\hline \multirow{3}{*}{ Konteks } & \multirow{2}{*}{ Primer } & $\begin{array}{l}\text { Wawancara mendalam dengan } \\
\text { Pengasuh dan Pengurus Pondok } \\
\text { Pesantren }\end{array}$ \\
\hline & & $\begin{array}{l}\text { Dokumentasi tertulis dari hasil interaksi } \\
\text { antara anggota warga Pondok Pesantren } \\
\text { (budaya organisasi) }\end{array}$ \\
\hline & Sekunder & $\begin{array}{l}\text { Dokumentasi terkait sistem organisasi } \\
\text { (profil organisasi dan lain-lain yang } \\
\text { relevan) }\end{array}$ \\
\hline
\end{tabular}

Setelah dilakukan analisis data teks dan data konteks, pada tahap pembahasan akan dilakukan diskusi teori. Teori yang digunakan dalam penelitian ini adalah Teori Naratif Fisher untuk melihat adanya Rasionalitas Naratif pada narasi di masing-masing komunitas lokal. Konsep rasionalitas naratif yang dijelaskan Fisher memiliki dua prinsip. 
Gambar 2. Kerangka Penelitian Kontra-Narasi Terorisme dan Kekerasan Agama di Pondok Pesantren

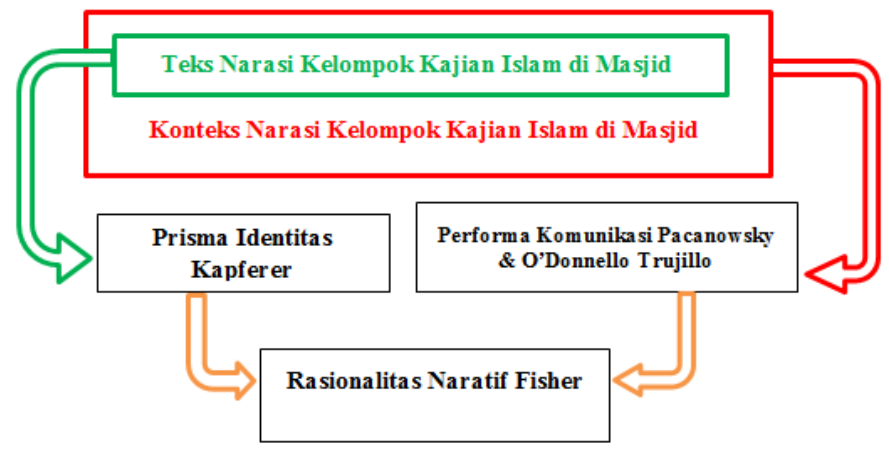

\section{Hasil Dan Pembahasan}

\subsection{Koherensi Struktural}

Struktur narasi pondok Pesantren memiliki koherensi antara satu elemen dengan elemen lainnya, yang akan dijelaskan pada tabel berikut:

Tabel 2. Struktur Teks Narasi dengan tema Toleransi pada Perbedaan

\begin{tabular}{llll}
\hline Tujuan & Tindakan yang & Khalayak saat ini & Nilai moral \\
& diharapkan & & \\
\hline Membentuk & Tidak mudah memvonis & Perang saudara terjadi & Al-Quran \\
pemahaman & muslim & karena perbedaan yang & menjelaskan Islam \\
bahwa & (individu/kelompok) & tidak bisa ditolerir dan & sebagai agama \\
perbedaan & yang melakukan cara & dikelola, disebabkan & damai dan \\
adalah sesuatu & beribadah yang & karena toleransi pada & menganjurkan \\
yang lumrah & dianggap berbeda. & perbedaan yang tidak & Muslim dengan non- \\
dan hal yang & Pondok pesantren, & ditanamkan, serta & muslim tetap \\
biasa di & membentuk masyarakat & pertumbuhan dan & memiliki hubungan \\
lingkungan & damai dalam & penyebaran kelompok & sosial dan tetap \\
sosial. & perbedaan, dengan & takfiri. & berbuat baik kepada \\
& menanamkan sikap & & sesama manusia \\
& toleransi sejak dini pada & & tanpa memandang \\
& santri maupun juga & & agamanya, serta \\
& kepada masyarakat & & perintah agar umat \\
& luas. & & Islam tetap bersatu \\
& & & dan tidak berpecah \\
& & & belah \\
\hline
\end{tabular}

Tabel 3. Struktur Teks Narasi dengan Tema Perbedaan Pilihan Politik

\begin{tabular}{|c|c|c|c|}
\hline Tujuan & Tindakan yang diharapkan & Khalayak saat ini & Nilai moral \\
\hline $\begin{array}{l}\text { Menjaga } \\
\text { persatuan umat } \\
\text { Islam, dan } \\
\text { keutuhan negara } \\
\text { Indonesia yang } \\
\text { dikenal sebagai } \\
\text { negara yang }\end{array}$ & $\begin{array}{l}\text { Nahdliyin (warga NU) } \\
\text { khususnya, tidak } \\
\text { mudah percaya kritis } \\
\text { terhadap narasi dan } \\
\text { berita pemecah umat } \\
\text { yang diciptakan oleh } \\
\text { kelompok-kelompok }\end{array}$ & $\begin{array}{l}\text { Terdapat pihak yang } \\
\text { memiliki kepentingan } \\
\text { politik akan } \\
\text { menggunakan isu-isu } \\
\text { agama untuk memecah } \\
\text { belah dan } \\
\text { memprovokasi umat }\end{array}$ & $\begin{array}{l}\text { Nilai yang } \\
\text { bersumber dalam Al- } \\
\text { Quran dan } \\
\text { keputusan para } \\
\text { Ulama serta GP } \\
\text { Ansor, Nahdlatul } \\
\text { Ulama yang memiliki }\end{array}$ \\
\hline
\end{tabular}




\begin{tabular}{|c|c|c|c|}
\hline $\begin{array}{l}\text { memiliki umat } \\
\text { Islam terbesar di } \\
\text { dunia. }\end{array}$ & $\begin{array}{l}\text { yang dianggap } \\
\text { menyimpang. }\end{array}$ & $\begin{array}{l}\text { dengan berita dan } \\
\text { informasi yang tidak } \\
\text { benar. }\end{array}$ & $\begin{array}{l}\text { keterkaitan dengan } \\
\text { perintah kepada } \\
\text { umat Islam untuk }\end{array}$ \\
\hline $\begin{array}{l}\text { Membangun } \\
\text { pandangan } \\
\text { positif tentang } \\
\text { perbedaan politik } \\
\text { dan mencegah } \\
\text { perpecahan umat } \\
\text { Islam karena } \\
\text { perbedaan } \\
\text { politik. }\end{array}$ & $\begin{array}{l}\text { Silaturrahmi dengan } \\
\text { kelompok Islam lain }\end{array}$ & $\begin{array}{l}\text { Masyarakat Indonesia } \\
\text { dianggap kerap } \\
\text { berhadapan dengan } \\
\text { konflik yang disebabkan } \\
\text { karena perbedaan } \\
\text { kelompok, salah } \\
\text { satunya perbedaan } \\
\text { politik }\end{array}$ & $\begin{array}{l}\text { tidak mudah percaya } \\
\text { pada sebuah isu dan } \\
\text { juga berita yang } \\
\text { belum memiliki } \\
\text { kejelasan data dan } \\
\text { tidak memiliki bukti } \\
\text { dan fakta }\end{array}$ \\
\hline
\end{tabular}

Tabel 4. Struktur Teks Narasi dengan tema Makna Jihad

\begin{tabular}{|c|c|c|c|}
\hline Tujuan & & Khalayak saat ini & Nilai moral \\
\hline $\begin{array}{l}\text { Memberikan definisi } \\
\text { alternatif kepada } \\
\text { khalayak mengenai jihad. }\end{array}$ & \multirow{3}{*}{$\begin{array}{l}\text { Santri diharapkan dapat } \\
\text { berprofesi di bidang } \\
\text { apapun dengan tetap } \\
\text { menerapkan nilai-nilai } \\
\text { Islam, sehingga } \\
\text { perkembangan Islam } \\
\text { muncul di bidang } \\
\text { tersebut. Pesantren pun } \\
\text { diharapkan melakukan } \\
\text { reformasi sistem } \\
\text { pendidikan dan } \\
\text { pendekatan pola } \\
\text { berfikir yang lebih } \\
\text { modern. }\end{array}$} & \multirow{3}{*}{$\begin{array}{l}\text { Selama ini mayoritas } \\
\text { santri hanya } \\
\text { menekuni pekerjaan } \\
\text { pada sektor swasta } \\
\text { dan jarang yang } \\
\text { bekerja sebagai } \\
\text { militer termasuk } \\
\text { sebagai profesional. } \\
\text { Hal tersebut } \\
\text { diakibatkan oleh } \\
\text { beberapa pesantren } \\
\text { yang hanya } \\
\text { mengkaji ilmu } \\
\text { agama dan faktor- } \\
\text { faktor lainnya. }\end{array}$} & \multirow{3}{*}{$\begin{array}{l}\text { Nilai-nilai } \\
\text { budaya } \\
\text { dimana narasi } \\
\text { ini dibentuk } \\
\text { menjadi } \\
\text { pendukung } \\
\text { narasi ini, atau } \\
\text { dengan kata } \\
\text { laian, nilai } \\
\text { budaya lokal } \\
\text { yang juga } \\
\text { menjadi } \\
\text { pendukung } \\
\text { nilai-nilai } \\
\text { agama. }\end{array}$} \\
\hline $\begin{array}{l}\text { Selain itu pula, untuk } \\
\text { mengembalikan Islam } \\
\text { sebagai agama yang } \\
\text { membawa pesan damai } \\
\text { (Rahmatan Lil Alamin), }\end{array}$ & & & \\
\hline $\begin{array}{l}\text { Mengembalikan masa } \\
\text { jaya kaum muslimin } \\
\text { sebagai pelopor } \\
\text { munculnya berbagai } \\
\text { bidang ilmu } \\
\text { pengetahuan. }\end{array}$ & & & \\
\hline
\end{tabular}

\subsection{Koherensi Material}

Keterkaitan antar-narasi pondok pesantren dapat dilihat dalam tabel berikut ini:

Tabel 5. Keterkaitan Antara Narasi milik Pondok Pesantren

\begin{tabular}{|c|c|c|c|}
\hline $\begin{array}{l}\text { Tema } \\
\text { Narasi }\end{array}$ & Tujuan Utama narasi & $\begin{array}{l}\text { Tindakan } \\
\text { diharapkan }\end{array}$ & Khalayak saat ini \\
\hline $\begin{array}{l}\text { Toleransi } \\
\text { dalam } \\
\text { Perbedaan }\end{array}$ & \multirow{3}{*}{$\begin{array}{l}\text { Menjaga persatuan } \\
\text { umat Islam, dan } \\
\text { keutuhan Negara, dari } \\
\text { perpecahan yang } \\
\text { disebabkan karena } \\
\text { perbedaan politik } \\
\text { dengan cara } \\
\text { membangun } \\
\text { pandangan positif } \\
\text { sebuah perbedaan di } \\
\text { masyarakat. }\end{array}$} & \multirow{3}{*}{$\begin{array}{l}\text { Saling memahami } \\
\text { dan menghargai } \\
\text { perbedaan, tidak } \\
\text { saling menyakiti. } \\
\text { Perbedaan adalah } \\
\text { sesuatu yang pasti } \\
\text { ada dan } \\
\text { seharusnya hal } \\
\text { tersebut dianggap } \\
\text { sebagai rahmat. }\end{array}$} & \multirow{3}{*}{$\begin{array}{l}\text { Umat Islam terbagi dalam } \\
\text { kelompok-kelompok dan } \\
\text { beberapa diantaranya sedang } \\
\text { berada dalam kondisi perang } \\
\text { saudara yang disebabkan } \\
\text { karena sebuah ideologi atau } \\
\text { provokasi. Baik yang dilakukan } \\
\text { oleh kelompok radikal atas } \\
\text { nama agama atau kelompok di } \\
\text { luar keagamaan. }\end{array}$} \\
\hline $\begin{array}{l}\text { Perbedaan } \\
\text { Pilihan } \\
\text { Politik } \\
\end{array}$ & & & \\
\hline $\begin{array}{l}\text { Makna } \\
\text { Jihad }\end{array}$ & & & \\
\hline
\end{tabular}




\subsection{Koherensi Karakterologis}

Karakter atau tokoh dalam narasi yang diproduksi oleh Pondok Pesantren sebagai cara meyakinkan anggota atau khalayak memiliki kesamaan antara satu dengan lainnya, dijelaskan sebagai berikut:

Tabel 6. Karakteristik Tokoh dalam Narasi milik Pondok Pesantren

\begin{tabular}{ll}
\hline \multicolumn{1}{c}{ Tema Narasi } & \multicolumn{1}{c}{ Karakteristik tokoh dalam narasi } \\
\hline $\begin{array}{l}\text { Toleransi pada } \\
\text { Perbedaan }\end{array}$ & $\begin{array}{l}\text { Nabi Muhammad SAW, diceritakan sebagai sosok yang tidak } \\
\text { senang memberikan stigma negatif kepada sesama muslim dan } \\
\text { kepada sahabatnya. } \\
\text { Makna Jihad }\end{array}$ \\
\hline & $\begin{array}{l}\text { Tidak hanya menjadikan kata jihad sebagai perang. } \\
\text { dibanding dengan jalan perang dan kekerasan. }\end{array}$ \\
\hline Organisasi Afiliasi (NU): NU adalah organisasi yang memiliki tugas \\
menjaga persatuan umat dan bangsa Indonesia di tengah \\
perbedaan. Organisasi NU mewakili Ahlusunnah wal jamaah di \\
Indonesia untuk merawat tali persatuan umat Islam dan juga \\
dengan pemeluk agama lain demi terjaganya Negara Kesatuan \\
Republik Indonesia
\end{tabular}

\subsection{Kebenaran (Kesejajaran Naratif)}

Setelah melakukan wawancara dan observasi, ditemukan beberapa kegiatan yang dilakukan oleh pihak pemilih dan pengurus Pondok Pesantren untuk mendukung narasi yang telah dibentuk agar pencegahan terorisme dan kekerasan agama di Pondok Pesantren lebih maksimal. Dalam konsep kontranarasi terorisme milik Archetti, hal tersebut disebut dengan Kesejajaran Narasi. Kesejajaran antara narasi dan tindakan yang dilakukan oleh Pondok Pesantren untuk mendukung narasi yang dimiliki dijelaskan melalui tabel berikut:

Tabel 7. Konsistensi antara Narasi dan Tindakan Pencegahan Terorisme di

\section{Pondok Pesantren}

$\begin{array}{ll}\text { Tema narasi } & \text { Fokus utama Narasi } \\ \text { Toleransi } & \text { Terbentuknya masyarakat } \\ \text { pada } & \text { yang damai dalam } \\ \text { Perbedaan } & \text { perbedaan, dan toleran } \\ \text { Keyakinan } & \end{array}$

Tindakan yang dilakukan

Mengajarkan dan menanamkan nilai-nilai Islam sebagai agama kasih sayang dalam setiap forum.

Dan juga ceramah-ceramah oleh pengurus pesantren tentang akhlak, dan bahaya radikalisme.

Pesantren kilat juga dibuka untuk umum, sehingga siapapun di luar pesantren yang ingin belajar tentang Islam Ahlussunnah wal jamaah. Pengurus Pesantren mengecek kurikulum yang bersumber dari pemerintah, untuk mencegah masuknya paham-paham takfiri.

Perbedaan Islam Radikal dianggap Pilihan Politik sebagai tantangan yang Pengasuh pesantren menciptakan narasi-narasi pencegahan terorisme, yang disampaikan menghadang persatuan umat Islam dan kemajuan bangsa Indonesia. Gerakan dalam forum keagamaan, di kelas, ditulis dalam blog pribadinya dan juga ditulis menjadi sebuah buku. 


$\begin{array}{ll} & \text { transnasional dianggap } \\ & \text { menguasai dunia maya } \\ & \text { dan melancarkan } \\ & \text { pergerakannya di dunia } \\ & \text { nyata. } \\ \text { Makna Jihad } \quad \text { Turut serta dalam upaya } & \text { perkembangan Islam } \\ & \text { sebagai agama yang } \\ & \text { membawa pesan damai, } \\ & \text { bukan agama teror. } \\ & \text { serta mengembalikan } \\ & \text { masa jaya kaum muslimin } \\ & \text { sebagai pelopor } \\ & \text { munculnya berbagai } \\ & \text { bidang ilmu pengetahuan. }\end{array}$

Berafiliasi dengan Nahdlatul Ulama sehingga menjadikan Pesantren ini sangat mengaplikasikan budaya-budaya sosial yang diajarkan oleh organisasi tersebut salah satunya sopan santun Mereformasi sistem pendidikan dengan membentuk MTS setara SMP, dan MA setara SMA. Sehingga santri lebih mudah melanjutkan pendidikan ke jenjang yang lebih tinggi.

\section{Penutup}

5.1. Kesimpulan

Setelah dilakukan analisis teks narasi dan diskusi teori untuk mengetahui Koherensi Narasi, diketahui teks narasi milik Pondok Pesantren dominan memiliki koherensi pada aspek tujuan (physique), cara melihat khalayak (self-image), hal yang diharapkan (reflect-consume) dan juga karakter yang digunakan dalam narasi (personality). Tujuan utama narasi adalah produksi pesan damai agar Indonesia tetap menjadi negara dengan masyarakat yang toleran dan dapat mengelola perbedaan yang ada. Penuturan sejarah menjadi pendukung elemen dalam narasi yang disusun untuk menjaga persatuan dan melawan ideologi takfiriyang selama ini dianggap sebagai penyebab terjadinya perpecahan di beberapa dunia Islam selama ini. Narasi milik Pondok Pesantren diperkuat dengan munculnya tokoh Nabi Muhammad yang pada intinya digambarkan sebagai sosok yang tidak menjadikan kata jihad hanya bermakna perang; mengedepankan musyawarah dalam menyelesaikan masalah dengan umat muslim maupun dengan kelompok agama lain. Dengan didasari afiliasi organisasi dan kultur, Organisasi Nahdlatul Ulama juga muncul dan digambarkan sebagai sebuah organisasi yang memiliki tugas menjaga persatuan umat dan bangsa Indonesia di tengah perbedaan.

Setelah mengintegrasikan hasil analisis teks dan konteks narasi, ditemukan bahwa upaya yang dilakukan oleh pihak Pondok Pesantren untuk mendukung narasi yang mereka miliki, adalah dengan cara rutin mengajarkan dan menanamkan nilai-nilai Islam sebagai agama kasih sayang dalam setiap forum. Pondok Pesantren juga membuka program pesantren kilat untuk masyarakat umum, sehingga siapapun di luar pesantren yang ingin belajar tentang Islam Ahlussunnah wal jamaah. Pesantren Al-Khoirot pun melakukan reformasi sistem pendidikan dengan membentuk kurikulum formal selain kurikulum agama Islam. Selain itu, dilakukan upaya untuk menangkal pemikiran radikalisme dengan mengecek kurikulum yang bersumber dari pemerintah atau dari luar. Pengasuh 
pesantren pula rutin menciptakan narasi-narasi pencegahan terorisme, yang disampaikan dalam forum di pesantren.

Dari hal tersebut diatas, disimpulkan bahwa Narasi Pondok Pesantren dalam penelitian ini sesuai dengan Visi Indonesia 2045 dan Impian Indonesia 2015 - 2085, dalam hal Pertahanan dan Keamanan untuk mewujudkan Identitas ke-Indonesia-an di atas batas identitas suku bangsa, agama, ras, dan golongan; serta untuk mewujudkan keamanan insani yang berpadu dengan keamanan nasional berlandaskan nilai-nilai kemanusiaan dan kemitraan seluruh komponen bangsa. Tidak hanya pondok pesantren, namun juga kampus, sekolah formal serta komunitas lokal yang bahkan tidak memiliki keterkaitan dengan identitas agama tertentu. Selain itu, program yang dilakukan oleh Pondok Pesantren AlKhoirot sejalan dengan Rancangan Kerja Pemerintah tahun 2019, seperti pemantapan nilai-nilai kebangsaan ke masyarakat luas, pelibatan masyarakat dalam pencegahan terorisme, meningkatkan harmoni sosial dan kerukunan dengan membentuk desa sadar kerukunan, serta yang penting adalah penyusunan dokumen counter-narrative strategy.

\subsection{Saran}

Berdasarkan penelitian ini diharapkan dalam pembentukan narasi pencegahan terorisme di pondok pesantren, tidak hanya sebatas membentuk narasi dengan hanya melihat satu aspek saja, namun harus memenuhi enam aspek dalam Prisma Identitas. Narasi pencegahan terorisme yang dibangun oleh pondok pesantren selanjutnya tidak lagi berdiri sendiri. Artinya bahwa sekumpulan narasi yang telah diproduksi harus memiliki konsistensi antara satu narasi dengan narasi yang lain. Narasi yang telah ada pula seharusnya didukung dengan kegiatan yang melibatkan seluruh civitas pondok pesantren. Begitupun sebaliknya, dimana kegiatan yang telah dilakukan harus didukung dengan sebuah narasi yang terus disampaikan kepada khalayak. Seluruh pesantren memiliki narasi masing-masing, dan narasi tersebut seharusnya diteliti untuk mengetahui benang merah antara narasi dan kegiatan yang sejalan dengan Visi Indonesia 2045.

Sesuai dengan Visi Indonesia 2045 dan Impian Indonesia 2015 - 2085, dalam hal Pertahanan dan Keamanan untuk mewujudkan keamanan insani yang berpadu dengan keamanan nasional berlandaskan nilai-nilai kemanusiaan dan kemitraan seluruh komponen bangsa, keikutsertaan kelompok atau organisasi di daerah tidak hanya sampai pada pondok pesantren, sehingga diharapkan hal yang sama juga dilakukan oleh komunitas lokal di seluruh daerah. Metode dalam penelitian ini dapat menjadi acuan pihak pemerintah (yakni BNPT dan FKPT) untuk mengecek narasi yang digunakan oleh komunitas lokal untuk melawan narasi terorisme dan kekerasan agama yang mengancam persatuan NKRI, serta melihat kegiatan yang dilakukan oleh komunitas lokal untuk mendukung narasi yang telah dimiliki. 
VI. Daftar Pustaka

Dari Buku

Archetti, Christine. (2013). Understanding Terrorism in The Age of Global Media: A Communication Approach. UK: Palgrave Macmillan.

Archetti, Christine. (2014a). (Mis)Communication Wars, Terrorism, Counterterrorism and the Media. dalam David Welch (ed.). (2014). Propaganda, Power and Persuasion. London: IB Tauris. (Halaman 209224)

Archetti, Christine. (2014b). Narrative Wars: Understanding Terrorism in the Era of Global Interconnectedness. dalam Miskimmon, A. O'Loughlin, B. Roselle L. (ed). (2014). Forging the World: Strategic Narratives and International Relations. Ann Arbor: University of Michigan Press. (Halaman 218-245).

Archetti, Christine. (2014c) "Terrorism, Communication and the Media,". dalam C. Kennedy-Pipe, G. Cubb and S. Mabon (eds). (2015). Terrorism and Political Violence. London: Sage.

Azra, Azyumardi dkk. (2017). Reformulasi Ajaran Islam Jihad Khilafah dan Terorisme. Jakarta: Mizan.

Cook, Guy. (2005). Discourse of Advertising (Interface Series). London : Routledge

Fink, Naureen. Chowdhury and Barclay, Jack. (2013). Mastering the Narrative: .Counterterrorism Strategic Communication and the United Nations. Center on Global Counterterrorism Cooperation.

Griffin, Em. (2011). A Fist Look At Communication Theory. Eighth Edition. New York: Mc Grew Hill.

Lim, Merlyna. (2005). Islamic Radicalism and Anti-Americanism in Indonesia: The Role of the Internet, Washington; East-West Center.

Johnstone, Barbara. (2001). Discourse Analysis and Narrative. In Schiffrin, Deborah. Tannen, Deborah and Heidi E. Hamilton (ed). (2001). The Handbook of Discourse Analysis. USA: Blackwell Publishers Inc.

Kuswarno, Engkus. (2011). Metode Penelitian Komunikasi: Etnografi Komunikasi. Pengantar dan Contoh Penelitiannya. Bandung: Widya Padjajaran

Lincoln, Yvonna S. Lynham, Susan A. and Egon G. Guba. (2011). Paradigmatic Controversies, Contradictions, and Emergenging Confluences, Revisited. In Norman K. Denzin and Y. S. Lincoln (Eds). (2011). The SAGE Handbook of Qualitative Research. Thousand Oaks, CA: Sage.

Littlejohn, Stephen W., dan Karen A Foss. (2008). Theories of Human Communication. Ninth Edition. Wadsworth Publishing Company. Albuquerque. New Mexico.

Littlejohn, S. W., \& Foss, K. A. (2009). Encyclopedia of communication theory. (Vol. 1). Sage.

Nacos, Brigitte L. (2006). Terrorism/Counterterrorism and Media in the Age of Global Communication. United Nations University Global Seminar 
Second Shimame. Yamaguchi Session. Terrorism-A Global Challenge. 58 August 2006. Columbia University. Hal. 15-16.

Nissen, Thomas Elkjer. (2014). The Two 'New Blacks': Social Media and Narratives, and The Challenge of Measurement. NATO COE DAT

O'Donnell, Brett. Gray, David H. (2012). Media and State Sponsored Terrorism. Global Security Studies. Spring 2012, Volume 3, Issue 2.

O'Loughlin, Ben. (2016). Media Coverage of Terrorism. In Jackson, Richard (ed). (2016). Routledge Handbook of Critical Terrorism Studies. UK: Routledge.

Pace, R. Wayne. Faules, Don F. (2002). Komunikasi Organisasi: Strategi Meningkatkan Kinerja Perusahaan. Bandung: Remaja Rosdakarya.

Parker, David. Pearce, Julia M. Lindekilde. Lasse. Rogers, M. Brooke. (2017). Challenges for Effective Counterterrorism Communication: Practitioner Insights and Policy Implications for Preventing Radicalization, Disrupting Attack Planning, and Mitigating Terrorist Attacks. (Journal). Studies in Conflict \& Terrorism. UK: Taylor \& Francis Group.

Pawito. (2007). Penelitian Komunikasi Kualitatif. Yogyakarta: LKiS

Perešin, Anita. (2007). Mass Media and Terrorism. Medij. istraž. (god. 13, br. 1) 2007. (p5-22)

Samuel, Thomas Koruth. (2016). Radicalisation in Southeast Asia: A Selected Case Study of Daesh in Indonesia, Malaysia and The Philippines. Malaysia The Southeast Asia Regional Centre for Counter-Terrorism (SEARCCT).

Sobur, Alex. (2014). Komunikasi Naratif: Paradigma, Analisis, dan Aplikasi. Bandung: Rosda

Syuhud, A. Fatih. (2017). Ahlussunnah Wal Jamaah: Islam Wasathiyah Tasamih Cinta Damai. Malang: Pustaka AlKhoirot

Ubayasiri, Kasun. (2014). The Efficacy of Censorship as a Response to Terrorism in Robert S. Fortner and P. Mark Fackler. (2014). The Handbook of Media and Mass Communication Theory. Vol. 2. Chichester. UK: John Wiley \& Sons, Ltd,

Ubayasiri, Kasun. (2014). The Effiacy of Cencirship as a Response to Terrorism. dalam Fortner, Robert S. and Fackler, P. Mark (ed). (2014). The Handbook of Media and Mass Communication Theory, First Edition. UK: John Wiley \& Sons. Halaman798-818.

Weimann, Gabriel. (2014). New Terriorism and New Media. Washington, DC: Commons Lab of the Woodrow Wilson International Center for Scholars.

West, Richard. Turner, Lynn H. (2008). Pengantar Teori Komuniakasi: Analisis dan Aplikasi. Edisi 3 buku 1. Jakarta: Salemba

West, Richard. Turner, Lynn H. (2008). Pengantar Teori Komuniakasi: Analisis dan Aplikasi. Edisi 3 buku 2. Jakarta: Salemba

Woodward, Mark et. al. (2010). Muslim Education, Celebrating Islam and Having Fun As Counter-Radicalization Strategies in Indonesia. Perspektive on Terrorism, Vol.4, No. 4. (diakses dari www.terrorismanalysts.com, tanggal 29/09/2017) 
Zeiger, Sara. (2016). Counter-Narratives for Countering Violent Extremism (CVE) in South East Asia. Hedayah (diakses dari (http://www.hedayahcenter.org/Admin/Content/File-2792016102253.pdf pada tanggal 24 Januari 2018)

Dari Penelitian Jurnal/Tesis

Abubakar, Irfan. (2016). Effective Strategic Communication in Countering Radicalism in Indonesia. Asia Pacific Center for Security Studies.

Aly, Anne. Weimann-Saks, Dana. and Weimann, Gabriel. (2014). Making 'Noise' Online: An Analysis of the Say No to Terror Online Campaign. (Journal). "Perspectives on Terrorism".

Archetti, Cristina. (2004). Are the Media Globalising Political Discourse?: The War On Terrorism Case Study. International Journal of the Humanities. Volume 2, Number 2.

Anwar, Azzam. (2015). Peran Lembaga Konvensional dan IT dalam Mencegah Intoleransi dan Radikalisme di Jawa Timur. Badan Nasional Penanggulangan Terorisme. dari http://damailahindonesiaku.com/wpcontent/uploads/2015/09/Penelitian-Potensi-Radikal-Terorisme-diJawa-Timur.pdf pada tanggal 23 November 2017 pukul 19:25 WIB).

Hamad, Ibnu. (2007). Lebih Dekat dengan Analisis Wacana. Mediator. Vol. 8, No. 2, Desember 2007. Hal. 325-344

Ines Von Behr, et, al. (2013) Radicalisation in The Digital Era: The use of the internet in 15 cases of terrorism and extremism. Journal. RAND Corporation.

Prajartol, Nunung. (2004). Terorisme dan Media Massa: Debat Keterlibatan Media. Jurnal IImu Sosial dan IImu Politik. Volume 8, Nomor L, Juli 2004 (hal. 37 - 52)

Sumardewi, Luh Ashari. (2012). Upaya Indonesia dalam Memberantas Terorisme di Era Susilo Bambang Yudhoyono: Pendekatan Tentang Pengeboman di Wilayah Indonesia. (jurnal). Denpasar: Universitas Udayana. 